\title{
Who Are Today's Career Encoring Adults?
}

\author{
Hacking Life Shifts 2020
}
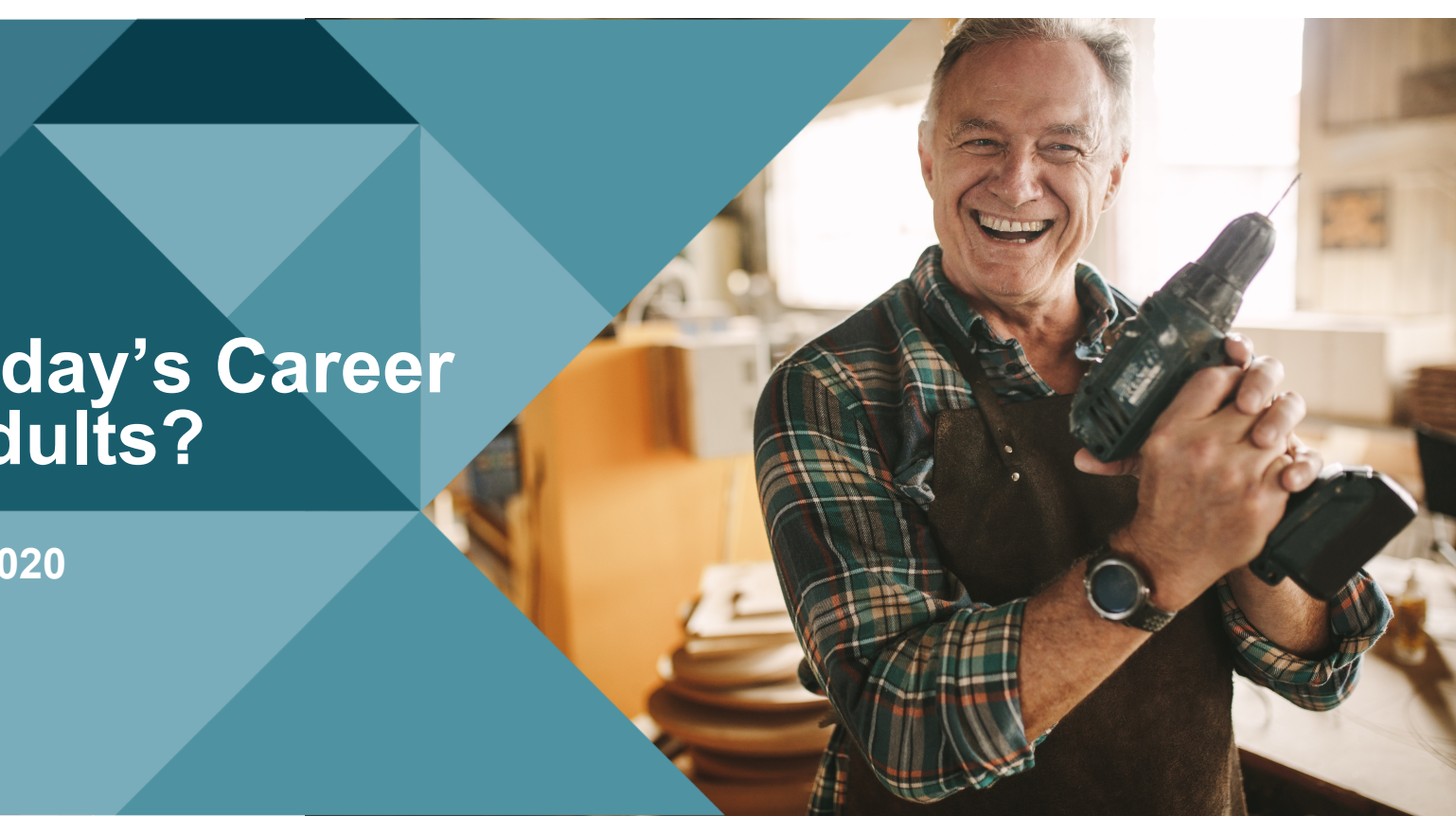

\section{Career Encoring: Executive Summary}

Career Encoring encompasses several different sub-segments, including those who have begun a new job, new career, or even a new business post retirement and those who volunteer. Often buoyed by a renewed sense of energy and purpose, most Career Encorers are highly motivated, emotionally and socially healthy, and active. They're also well rounded, making time for their personal interests and social life, in addition to their work. But there's another set of Career Encorers who are working out of necessity, who may have been forced out of their employment and feeling financially strained.

\section{Often buoyed by a renewed sense of energy and purpose, most Career Encorers are highly motivated, emotionally and socially healthy, and active.}

\section{Career Encoring: Health, Wealth \& Self}

The typical Career Encorer is older (mean age 69.6), a Boomer or Silent, more highly educated, with a higher-thanaverage income for US adults aged 45-plus. On average, this group has had nearly 40 -year careers before their Career Encore. The older the individual, the more years she or he spent in their careers prior to retirement.

Career Encorers are mostly white and almost equally male/female. Just more than half are now volunteering (averaging more than eight hours each week), and just less than half are working for pay. More than a third (38\%) are working parttime, $10 \%$ own their own business, and $5 \%$ are working full-time for their employers. Those who volunteer are slightly older. They also have achieved a higher education level and have the highest mean income of the various segments that comprise this shift.

A full three-quarters of Career Encorers say their retirement was planned. Those $25 \%$ who did not choose to retire report being let go or having to leave due to health reasons. This is the subgroup most likely to have experienced ageism in the workplace. They are much less confident in their social, emotional, and physical health and well-being; not surprisingly, 
then, they also experience lower levels of personal fulfillment. Because they have lower household incomes, they're under more financial pressure. More of this group is divorced or widowed than those who retired by choice, which adds to their financial pressure and explains even more as to why they don't feel fulfilled.

People in this Life Shift worry about boredom after their retirement. Those who were forced into their "post-retirement" role report feeling aimless and talk about the struggle to gain control over their life and find a meaningful path for themselves. In general, Career Encorers are intrinsically motivated and push themselves forward. Boomer men tend to work more hours in their Encore role than their female or Silent counterparts.

The majority of Career Encorers report no financial strain as a result of their retirement. However, $32 \%$ do feel strained - the most likely groups to feel strain are those who are working (as opposed to volunteering), as well as women female and younger Encorers.

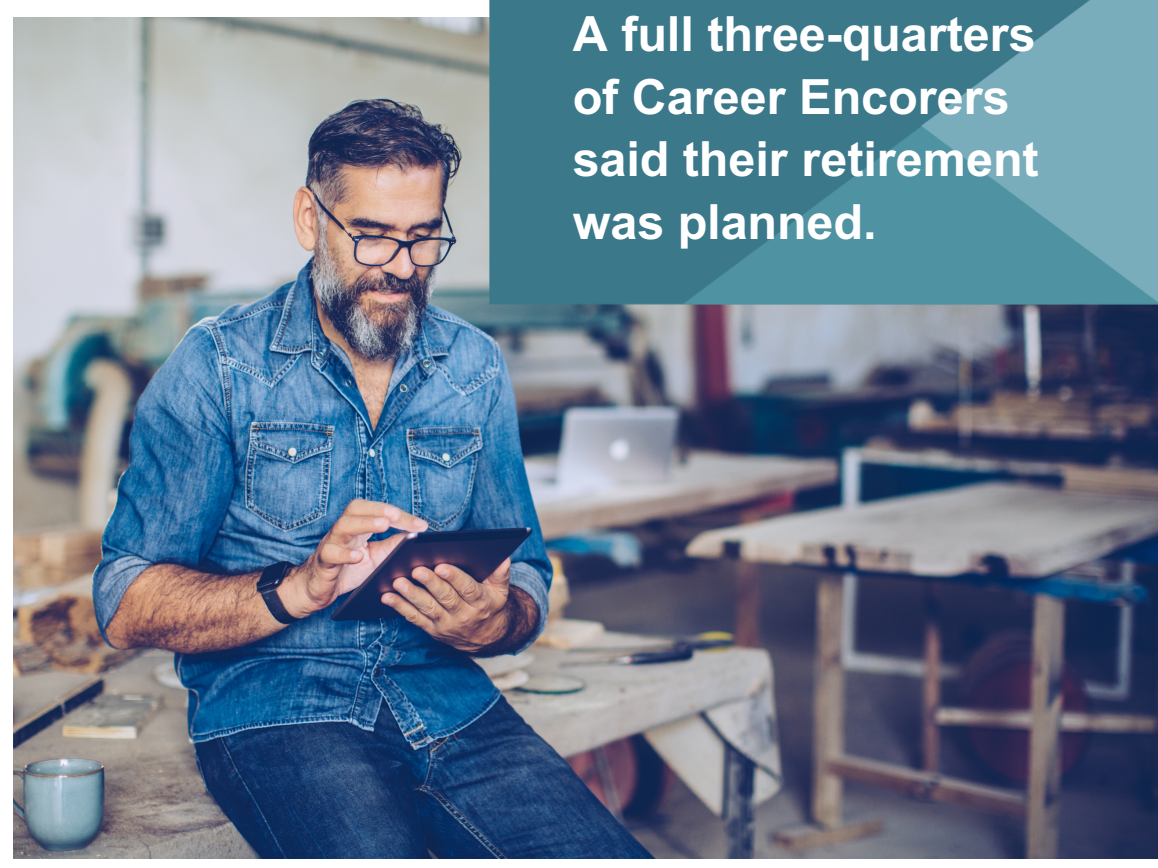

Those working for pay spend more weekly hours working than those who volunteer spend volunteering. Their motivations are markedly different. Volunteers do so because volunteering makes them happy while giving them a purpose and a place to go. Those who are employed are also looking to fill their days, but nearly a fourth (23\%) are doing so out of financial necessity. On the other hand, nearly half $(47 \%)$ choose to work for pleasure.

Two trends emerged from the qualitative research that straddle wealth and health. The first is the stress caused by moving from saving for retirement to a spending-down mentality. Even the most prepared retirees find this shift difficult and jarring.

More than three-quarters are fulfilled with their life, but this positivity is driven more by those who volunteer than those who are still working.
The other is the switch from private insurance to Medicare which often creates anxiety around navigating the different choices in coverage and making new health-related choices.

Attitudinally, this group is confident in its abilities, values independence, feels supported by family, and feels financially secure. More than three-quarters are fulfilled with their life, but this positivity is driven more by those who volunteer than those who are still working. Those who feel the most fulfilled tend to be older, married, and have a higher mean income. Those who are less fulfilled are more likely working out of necessity and have less support in the workplace.

Career Encorers, in the qualitative phase of this research, say that their health focus is squarely on their diet; not only in terms of how much they eat, but also the nutritious quality of the food they choose. They talked about being able to spend more time shopping to prepare better, healthier food. And, they appear to be more conscientious about and proactive when it comes to their physical health, with several talking about new gym memberships. 


\section{Resources for Career Encorers}

Career Encorers show high levels of awareness of products and services that can assist them with their finances and their physical, emotional, and social health. Just more than one-third have accessed resources for their physical health, but otherwise they use few services to help navigate this Life Shift.

Career Encorers are most likely to land in the Technology Novices category and are less focused on technology, which makes sense given the older average age of this group. Novices consider technology to be of limited impact on their life. Similarly, they fall into the Pragmatic Adopters of mobile phones, considering them more functional than fun. This finding is consistent with other research that shows Boomers view technology as a useful tool rather than as a social or entertainment centerpiece of their lives. They believe technology makes them more efficient and task oriented. While they do acknowledge tech's entertainment value, they say that their lives are full with activities offline. In spite of the "novice" status, they are among the most active online users because of their work.

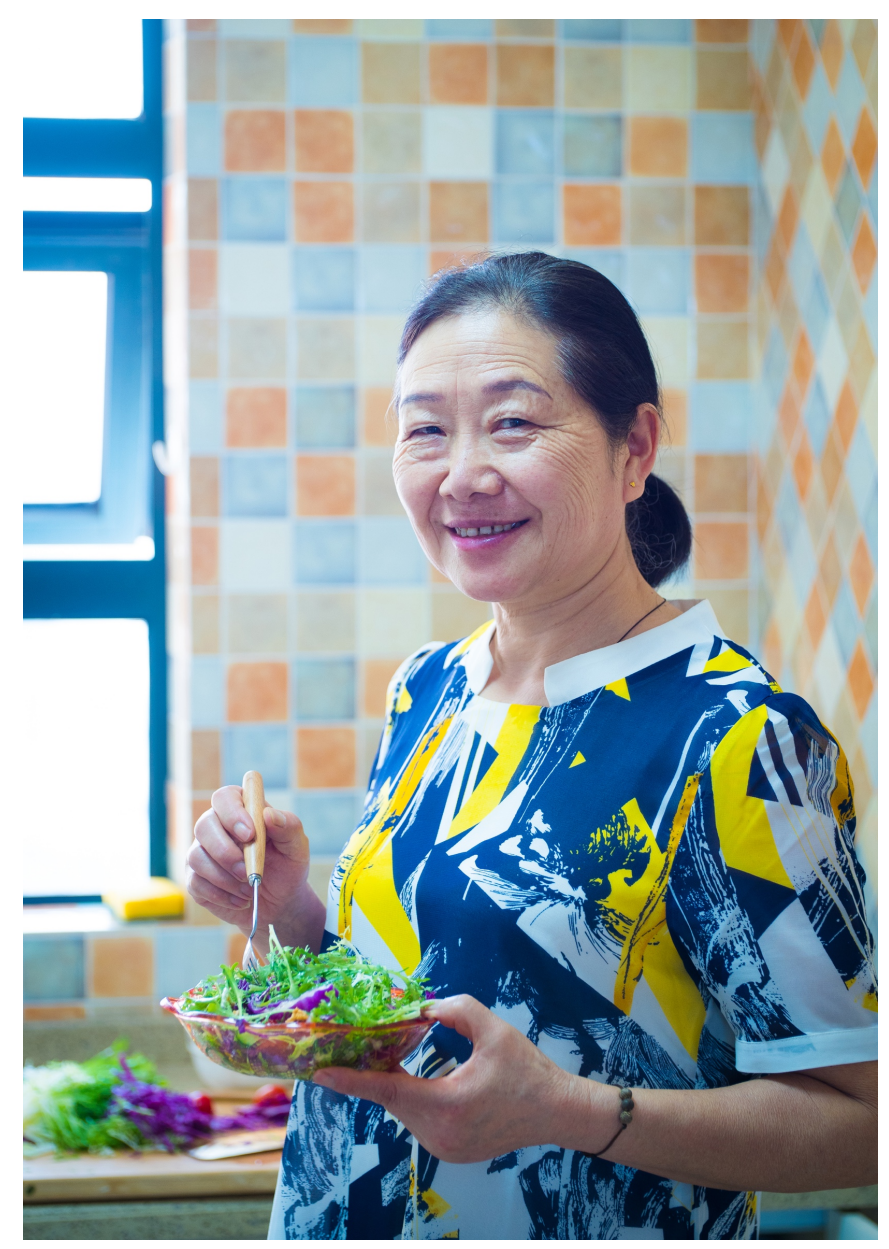

When seeking information to help them with this shift, both those who are working and those who are volunteering report consulting first with people they know. Fewer than one in five say they seek information relative to their Life Shift. Encorers believe they are resourceful and learn from others. They also say they value expertise. Volunteers are more likely to seek out both printed media and blogs for information and are twice as likely to rely on medical/mental health professionals for advice as those who are working again.

Career Encorers say they aren't doing a lot of shopping to specifically support this Life Shift. If they do, it's for smart technology or clothing, with insurance, gym memberships, and health-and-wellness products also noted. Volunteers shop more, particularly in the areas of insurance, gym memberships, financial services, and personal-care items. This difference is likely due to volunteers having more free time for shopping and other activities. The majority of Career Encorers' purchases are in retail stores, though 24\% report shopping online. Drug stores, department stores, and Walmart are their top brick-and-mortar locations.

Career Encoring is an upbeat and fulfilling Life Shift for the majority of those both working and volunteering. As noted, there's a less positive segment of this group forced into "retirement," who must work to support themselves and who subsequently report more struggles and less fulfillment with their lives. Overall, working and volunteering correlate to higher levels of engagement and more activities outside of work. Those who are choosing to work or volunteer are pioneering a new stage of life that will become a model for future generations. 


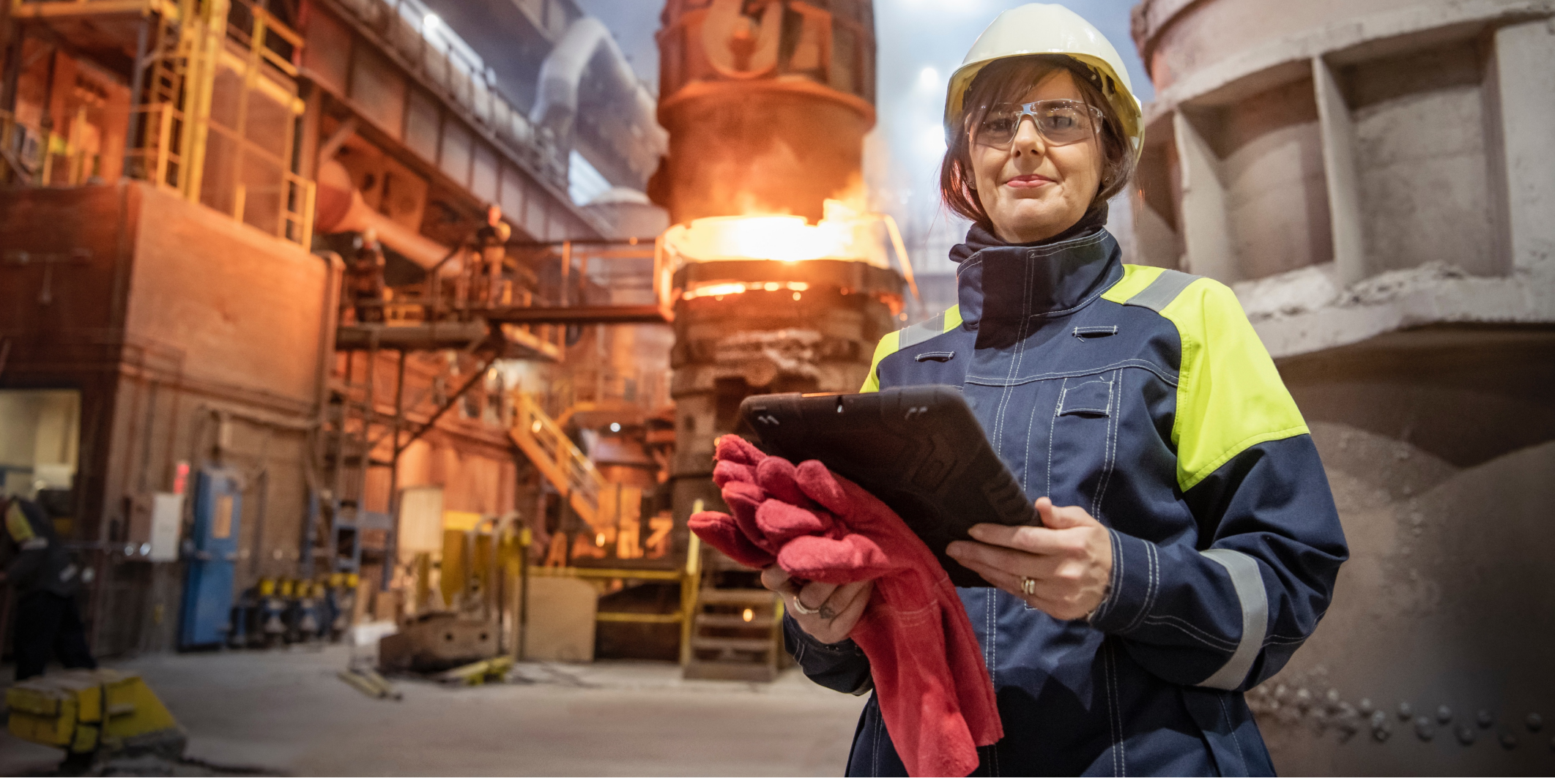

\section{About: The Five Life Shifts}

This new "Hacking Life Shifts" study dives deeply into five of the most provocative changes that can take place during the aging journey:

- Caregiving - providing ongoing informal care (usually for a spouse or parent)

- Recent Singles - moving to the next stage of life after a divorce or widowhood

- Grandparenting - becoming a grandparent

- Career Encoring - starting a new career or focusing on volunteering after ending life's work

- Changing Living Situation - relocating from one's current home to another location

None of these shifts takes place in a vacuum. Consumers frequently experience one or more at the same time. Moreover, this study focuses on recency of the shift. We recruited participants who are either immersed in the shift right now or have recently navigated through it, ensuring that the insights are fresh and the stories compelling.

\section{Methodology}

Hacking Life Shifts is a four phase research project combining secondary research, an online quantitative survey ( $n=2003$, ages 45-91), qualitative interviews and exercises, and behavioral data integration. For full methodology information, please see the Hacking Life Shifts: Methodology document. Career Encorers are defined as those who are

- Retired from "life's work" (main work activity or activities have been involved in during lifetime), or

- Started own business, doing full/part-time work or spending significant time volunteering (8+ hours/week).

Research led by RTi Research, The Business of Aging and aha: The Strategic Online Qual Platform. Powered by Collaborata.

\section{$\triangle 1 \mathrm{R}$ Real Possibilities}

For more information, contact Patty David, pdavid@aarp.org.

For media inquiries, contact media@aarp.org. 